\title{
Prognostic value of alcohol consumption and some other dietary habits for survival in a cohort of Chinese men with lung cancer
}

\author{
Wentao Li ${ }^{1}$, Lap Ah Tse ${ }^{1 *}$, Joseph S. K. Au ${ }^{2}$, Kai Shing Yu ${ }^{1}$, Feng Wang ${ }^{1}$ and Ignatius Tak-sun Yu ${ }^{1}$
}

\begin{abstract}
Background: Alcohol consumption and some other dietary habits are thought to be associated with lung cancer incidence. However, the effects of these habits on lung cancer prognosis have been studied rarely. The purpose of this study was to address these gaps in knowledge.

Methods: We studied a cohort of 1052 Chinese men in Hong Kong who were diagnosed with primary lung cancer. Cox proportional hazards models were used to determine the prognostic values of consumption of alcohol, fresh fruits or vegetables, meat, and fried or preserved food.

Results: Compared with never drinkers, men who drank alcohol 1-3 days per week had a more favorable lung cancer prognosis (hazard ratio [HR]: 0.82, 95\% confidence interval [Cl] 0.68-0.97); however, this survival advantage was not significant in men who drank alcohol more frequently (HR: 0.91, 95\% Cl 0.73-1.14). Compared with men who consumed preserved or fried food only occasionally, men who consumed these foods frequently had a higher risk of lung cancer mortality (HR: 1.20, 95\% Cl 1.00-1.42).

Conclusions: Occasional consumption of alcohol was a favorable survival factor for Chinese men with lung cancer. However, this survival benefit did not exist for frequent drinkers of alcohol. Chinese men with lung cancer who were frequent consumers of fried or preserved food had a worse prognosis than those who consumed these foods only occasionally.
\end{abstract}

Keywords: Dietary habits, Alcohol, Lung cancer, Prognosis, Epidemiology

\section{Background}

Worldwide, for centuries lung cancer has been the leading cause of cancer-related death [1]. In China, lung cancer is the most common and most deadly type of cancer $[2,3]$. Because of the deterioration of air quality, the incidence of lung cancer is expected to increase [4]. The association between lung cancer risk and lifestyle is an emerging concern. However, the findings of several studies on the association between frequent alcohol drinking and lung cancer risk have been controversial and unconvincing, mainly because of the residual confounding

\footnotetext{
*Correspondence: shelly@cuhk.edu.hk

1 JC School of Public Health and Primary Care, The Chinese University of Hong Kong, 4/F School of Public Health and Primary Care, Prince of Wales Hospital, Sha Tin, N.T., Hong Kong SAR, China

Full list of author information is available at the end of the article
}

effect of tobacco smoking [5, 6]. Meanwhile, epidemiologic studies have shown that lung cancer risk is inversely related to the frequent consumption of fruits or vegetables $[7,8]$ and positively associated with meat consumption [9-12]. A previous study of ours indicated that the frequent consumption of preserved or fried food is also related to lung cancer risk [12].

Many studies have focused on the relationship between lifestyle and lung cancer risk; in contrast, very few studies have investigated the association between lifestyle and the prognosis of lung cancer patients. This is perhaps because most of the studies on lung cancer survival have been focused on the prognostic value of tumor characteristics and treatments. However, some either carcinogenic or protective habits may have significant effects on cancer progression; some carcinogens may also have 
the potential to promote tumor progression. Furthermore, lifestyle habits are modifiable, and cancer patients may improve their prognosis by adopting more favorable habits. To date, no study has investigated the effects of consumption of alcohol, meat, and fried or preserved food on lung cancer prognosis, and very few studies have examined the association of fresh fruit or vegetable consumption with lung cancer prognosis. The purpose of this study was to address these gaps in knowledge.

\section{Methods}

\section{Study population}

We consecutively recruited 1208 Chinese men who had histologically confirmed lung cancer. These patients were from a completed population case-control study conducted at the Department of Clinical Oncology of Queen Elizabeth Hospital in Hong Kong during the period of February 2004 to September 2006. The response rate was 96\%. Patients were considered eligible if they were diagnosed with primary lung cancer. Patients who were older than 80 years were excluded. The Department of Clinical Oncology of Queen Elizabeth Hospital, which serves approximately one-fourth of all local cases, is the largest lung cancer center in Hong Kong. The age distribution of patients and the histologic subtypes of lung cancer that were reported by the Queen Elizabeth Hospital were similar to those reported by the Hong Kong Cancer Registry [12]. Details of the recruitment process have been described previously $[13,14]$. Ethics agreements of the study were obtained from the ethics committees of both the Chinese University of Hong Kong and Queen Elizabeth Hospital (KC/KE 04-0014/ER-1, KC/KE 08-0028/ ER-2). Written consent forms were obtained from all patients.

\section{Information collection}

A structured questionnaire was used by trained interviewers to collect information on patients' cigarette smoking, alcohol consumption, and dietary habits, as well as other related factors. Patients were classified as never smokers (smoking $<20$ packs of cigarettes in a lifetime or $\leq 1$ cigarette per day for 1 year); former smokers (quit smoking $\geq 2$ years ago); and current smokers (still smoking or quit $<2$ years ago). Current and former smokers were asked for information about daily cigarette smoking, years of smoking, and years since cessation (if they quit). In terms of alcohol consumption, patients were asked to report whether they had consumed alcoholic beverages [beer, red wine, white wine (including rice wine), and liquor] during the past year. If the answer was "yes," they were classified as drinkers, and then they were asked about their frequency of consumption. Patients who drank alcohol 1-3 days per week were classified as occasional drinkers, whereas those who drank more often were classified as frequent drinkers. We did not, however, collect information about the quantity of alcohol (i.e., grams per day) that the patients consumed. In terms of dietary habits, patients were asked for information on their consumption of fresh fruits or vegetables, meat, and preserved or fried food. Patients were classified as occasional consumers if their average consumption was less than one serving per day (one serving $=80 \mathrm{~g}$ ); if patients consumed one or more servings per day, they were classified as frequent consumers. Information on body mass index (BMI, $\mathrm{kg} / \mathrm{m}^{2}$ ), age at diagnosis, comorbidity (translated into the Charlson Comorbidity Index), cancer stage at diagnosis, and treatment type (surgery, chemotherapy, radiotherapy, alternative therapy, or combination therapy) was obtained from patients' referral letters, medical records, and the clinical management system of Hong Kong. Additionally, information on histologic differentiation was obtained from pathologic reports.

\section{Follow-up}

The vital status of each patient was obtained by a passive surveillance method. This method involved reviewing information from several sources, including clinical discharge notes and the clinical management system of Hong Kong. The follow-up start date was the date of each patient's pathologic diagnosis of lung cancer. The last follow-up was conducted on December 31, 2008. Patients whose vital status could not be ascertained were considered lost to follow-up. The primary endpoint was allcause mortality or the last follow-up.

\section{Statistical analysis}

The Mantel-Haenszel Chi square test and Fisher's exact test were used for distribution analyses. An independent $t$ test and an analysis of variance test were used to compare means. Overall survival was considered the prognosis endpoint. After examining the proportionate assumption, Cox proportional hazards models were used to calculate the hazard ratios (HRs) and 95\% confidence intervals (CIs). Potential confounders were required to be associated with drinking/dietary habits and the survival outcome. Initially, we included the following as potential confounders in the "base" model: district of residence, age group, education level, marital status, family income, smoking status, smoking pack-years, years after smoking cessation, cancer history in first-degree relatives, incense burning habit, age at diagnosis, BMI, Charlson Comorbidity Index score, cancer stage at diagnosis, and treatment type. Variables that could alter the estimate by $10 \%$ or more were retained in the final model. Results were retested in non-small cell lung cancer (NSCLC) and small cell lung cancer (SCLC) patients. 
To examine the association between dietary habits and tumor histology, binary logistic regression models were employed.

\section{Results \\ Patient characteristics}

In total, the data of survival and alcohol drinking of 1052 patients were available. Of these patients, 951 had NSCLC, and 101 had SCLC. Median follow-up was 9.1 months (range 0-58.8 months). During follow-up, 869 patients died. Of the 1052 patients, 391 (37.1\%) were classified as never drinkers, $289(27.5 \%)$ as occasional drinkers, and $372(35.4 \%)$ as frequent drinkers. In terms of preserved or fried food consumption, 768 (73.0\%) patients were classified as occasional consumers, and the remaining $284(27.0 \%)$ were classified as frequent consumers. In terms of fresh fruit or vegetable consumption, $667(63.4 \%)$ patients were classified as occasional consumers, and 385 (36.6\%) were classified as frequent consumers. In terms of meat consumption, 941 (89.4\%) patients were classified as occasional consumers, and 111 (10.6\%) were classified as frequent consumers.

Baseline demographic and clinical characteristics grouped by the consumption level of alcohol and preserved or fried food are shown in Table 1. Patients who were 70 years of age and older, had an education level below college, and current smokers were more likely to be frequent consumers of alcohol and preserved or fried food. Current smokers were more likely to be frequent meat consumers. Occasional and frequent consumers of preserved or fried food had similar BMI levels.

\section{Dietary habits and lung cancer prognosis}

Confounding factors retained in the final model were district of residence, age at diagnosis, cancer history in firstdegree relatives, BMI, cancer stage at diagnosis, smoking status, smoking pack-years, and treatment type. Education level and family income were also retained in the final model because they were likely to affect the association between alcohol consumption and overall survival.

Lung cancer prognosis in relation to alcohol consumption and dietary habits is shown in Table 2. Compared with never drinkers, drinkers had a $17 \%$ lower risk of lung cancer death (HR: 0.83, 95\% CI 0.70-0.98). The observed favorable lung cancer prognosis in alcohol drinkers was restricted to occasional drinkers (HR: 0.82, 95\% CI $0.68-$ 0.97). Figure 1 illustrates the survival curve regarding alcohol consumption habits. Compared with occasional consumers of preserved or fried food, frequent consumers had a higher risk of lung cancer death (HR: 1.20, 95\% CI 1.00-1.42). Consumption of fresh fruits or vegetables and meat was not statistically associated with lung cancer death (Table 2).

\section{Subgroup analysis according to histologic types}

Hazard ratios were retested in NSCLC and SCLC cases (Table 3). For patients with NSCLC, the prognosis of occasional drinkers was better than that of never drinkers (HR: 0.74, 95\% CI 0.62-0.90). However, this survival advantage became non-significant in frequent drinkers (HR: 0.84, 95\% CI 0.70-1.02). Frequent consumption of preserved or fried food had an adverse effect on the prognosis of NSCLC patients (HR: 1.21, 95\% CI 1.00-1.45). Because the number of SCLC cases was small, all results in SCLC patients were not statistically significant.

\section{Alcohol consumption, dietary habits, and tumor histology}

The two confounding factors retained in the final model were age at diagnosis and smoking status. Table 4 shows the associations between alcohol drinking and dietary habits with lung cancer histology. Compared with SCLC patients, NSCLC patients were less likely to frequently consumed fruits or vegetables (odds ratio [OR]: 0.62, 95\% CI 0.41-0.95) and preserved or fried food (OR: 0.50, 95\% CI 0.33-0.76).

\section{Discussion}

In this study, we found that Chinese men with lung cancer who ever drank alcohol had a better prognosis than those who never drank alcohol (HR: 0.84, 95\% CI 0.72-0.98); however, the observed favorable prognosis in alcohol drinkers was restricted to occasional drinkers (HR: $0.80,95 \%$ CI 0.67-0.96). Furthermore, men who frequently consumed preserved or fried food had a higher risk of lung cancer death than occasional consumers (HR: $1.21,95 \%$ CI 1.02-1.43).

A similar U-shaped dose-responsive pattern between alcohol consumption and survival was found in some studies on breast cancer [15-17]. A meta-analysis indicated that moderate consumption of wine may have a chemopreventive effect on lung cancer, whereas consumption of beer may increase lung cancer risk [18]. Some in vitro studies suggested that polyphenols in wine can inhibit cancer cell proliferation and thus prolong survival $[19,20]$. Nevertheless, beer accounts for the majority of alcohol consumption in Hong Kong [21]; the benefit of wine polyphenols is unlikely to explain the observed survival advantage in drinkers.

Until now, there has been no evidence to suggest that the consumption of preserved or fried food affects lung cancer prognosis. Recently, animal studies confirmed that dietary acrylamide (a substance generated when food is fried) is mutagenic in mouse lungs [22]. Nitrite, a potential carcinogen in preserved food, might facilitate the process of lung cancer development; a high serum nitrite level might have a negative effect on the survival of lung cancer patients [23-25]. Consistent epidemiologic 
Table 1 Baseline demographic and clinical characteristics of 1052 Chinese men with lung cancer, grouped by level of alcohol consumption and consumption of preserved or fried food

\begin{tabular}{|c|c|c|c|c|c|}
\hline \multirow[t]{2}{*}{ Characteristic $^{a}$} & \multicolumn{3}{|l|}{ Alcohol $^{\mathbf{b}}$} & \multicolumn{2}{|l|}{ Preserved or fried food ${ }^{c}$} \\
\hline & Never $(n=391)$ & Occasional $(n=289)$ & Frequent $(n=372)$ & Occasional $(n=768)$ & Frequent $(n=284)$ \\
\hline \multicolumn{6}{|l|}{ Age group (years) } \\
\hline$<50$ & $33(8.4)$ & $28(9.7)$ & $18(4.8)$ & $65(8.5)$ & $20(7.0)$ \\
\hline $50-59$ & $62(15.9)$ & $58(20.1)$ & $62(16.7)$ & $142(18.5)$ & $39(13.7)$ \\
\hline $60-69$ & $144(36.8)$ & 97 (33.6) & $127(34.2)$ & $272(35.5)$ & $92(32.4)$ \\
\hline$\geq 70$ & $152(38.9)$ & $106(36.7)$ & $164(44.2)^{\wedge}$ & $288(37.5)$ & $133(46.8)^{\wedge}$ \\
\hline \multicolumn{6}{|l|}{ District of residence } \\
\hline New Territories & $65(17.3)$ & $49(17.3)$ & $50(13.9)$ & $126(16.9)$ & $38(13.9)$ \\
\hline Kwai Tsing & $30(8.0)$ & $30(10.6)$ & $34(9.5)$ & $67(9.0)$ & $27(9.9)$ \\
\hline Wong Tai Sin & $68(18.1)$ & $58(20.5)$ & $67(18.7)$ & $147(19.7)$ & $46(16.8)$ \\
\hline Kowloon City & $41(10.9)$ & $50(17.7)$ & $36(10.0)$ & $95(12.8)$ & $32(11.7)$ \\
\hline Yau Tsim Moog & $27(7.2)$ & $20(7.1)$ & $40(11.1)$ & $65(8.7)$ & $22(8.1)$ \\
\hline Sham Shui Po & $59(15.7)$ & $26(9.2)$ & $58(16.2)$ & $98(13.2)$ & $45(16.5)$ \\
\hline Others & $86(22.9)$ & $50(17.7)$ & $74(20.6)^{\wedge}$ & $147(19.7)$ & $63(23.1)$ \\
\hline \multicolumn{6}{|l|}{ Education level } \\
\hline Primary school & $102(26.2)$ & $50(17.3)$ & $110(29.6)$ & $179(23.4)$ & $84(29.6)$ \\
\hline Middle school & $162(41.5)$ & $134(46.4)$ & $168(45.3)$ & $326(42.6)$ & $136(47.9)$ \\
\hline College or above & $126(32.3)$ & $105(36.3)$ & $93(25.1)^{\wedge}$ & $261(34.1)$ & $64(22.5)^{\wedge}$ \\
\hline \multicolumn{6}{|l|}{ Marital status } \\
\hline Married & $62(15.9)$ & $44(15.2)$ & $68(18.3)$ & $130(16.9)$ & $45(15.8)$ \\
\hline Others & $329(84.1)$ & $245(84.8)$ & $304(81.7)$ & $638(83.1)$ & $239(84.2)$ \\
\hline \multicolumn{6}{|c|}{ Family income (Hong Kong dollars/month) } \\
\hline$<4000$ & $228(58.6)$ & $161(55.7)$ & $252(67.7)$ & $457(59.7)$ & $184(64.8)$ \\
\hline$\geq 4000$ & $100(25.7)$ & $88(30.4)$ & $79(21.2)$ & $198(25.8)$ & $69(24.3)$ \\
\hline Unknown & $61(15.7)$ & $40(13.8)$ & $41(11.1)^{\wedge}$ & $111(14.5)$ & $31(10.9)$ \\
\hline \multicolumn{6}{|l|}{ Smoking status ${ }^{\mathrm{d}}$} \\
\hline Never & $60(15.4)$ & $34(11.8)$ & $21(5.6)$ & $103(13.4)$ & $13(4.6)$ \\
\hline Former & $99(25.4)$ & $90(31.1)$ & $109(29.3)$ & $208(27.1)$ & $87(30.6)$ \\
\hline Current & $231(59.2)$ & $165(57.1)$ & $242(65.1)^{\wedge}$ & $456(59.5)$ & $184(64.8)^{\wedge}$ \\
\hline \multicolumn{6}{|c|}{ Cancer history in first-degree relatives } \\
\hline No & $262(67.2)$ & $189(65.4)$ & $232(62.5)$ & $476(62.1)$ & $206(72.5)$ \\
\hline Yes & $68(17.4)$ & $65(22.5)$ & $80(21.6)$ & $161(21.1)$ & $48(16.9)$ \\
\hline Not sure & $60(15.4)$ & $35(12.1)$ & $59(15.9)$ & $129(16.8)$ & $30(10.6)^{\wedge}$ \\
\hline \multicolumn{6}{|c|}{ Charlson comorbidity index } \\
\hline $0-2$ & $384(98.2)$ & $287(99.3)$ & $364(97.8)$ & $753(98.0)$ & $282(99.3)$ \\
\hline $3-6$ & $7(1.8)$ & $2(0.7)$ & $8(2.2)$ & $15(2.0)$ & $2(0.7)$ \\
\hline \multicolumn{6}{|l|}{ Stage at diagnosis } \\
\hline । & $52(13.3)$ & $30(10.4)$ & $36(9.7)$ & $90(11.7)$ & $28(9.9)$ \\
\hline$\|$ & $11(2.8)$ & $17(5.9)$ & $20(5.4)$ & $34(4.4)$ & $16(5.6)$ \\
\hline III & $105(26.9)$ & $92(31.8)$ & $129(34.7)$ & $243(31.6)$ & $80(28.2)$ \\
\hline IV & $118(30.2)$ & $79(27.3)$ & $94(25.3)$ & $219(28.5)$ & $72(25.3)$ \\
\hline Unknown & $105(26.9)$ & $71(24.6)$ & $93(25.0)$ & $182(23.7)$ & $88(31.0)$ \\
\hline \multicolumn{6}{|l|}{ Treatment } \\
\hline Surgery & $26(6.6)$ & $20(6.9)$ & $37(9.9)$ & $57(7.4)$ & $20(7.0)$ \\
\hline Chemotherapy & $52(13.3)$ & $40(13.8)$ & $38(10.2)$ & $94(12.2)$ & $34(12.0)$ \\
\hline Radiotherapy & $79(20.2)$ & $49(17.0)$ & 76 (20.4) & $140(18.2)$ & $62(21.8)$ \\
\hline Others & $8(2.0)$ & $7(2.4)$ & $14(3.8)$ & $18(2.3)$ & $11(3.9)$ \\
\hline No treatment & $122(31.2)$ & 95 (32.9) & $106(28.5)$ & $233(30.3)$ & $88(31.0)$ \\
\hline
\end{tabular}


Table 1 continued

\begin{tabular}{|c|c|c|c|c|c|}
\hline \multirow[t]{2}{*}{ Characteristic $^{a}$} & \multicolumn{3}{|l|}{ Alcohol $^{b}$} & \multicolumn{2}{|c|}{ Preserved or fried food ${ }^{c}$} \\
\hline & Never $(n=391)$ & Occasional ( $n=289)$ & Frequent $(n=372)$ & Occasional $(n=768)$ & Frequent $(n=284)$ \\
\hline Combination & $104(26.6)$ & $78(27.0)$ & $101(27.2)$ & $226(29.4)$ & $69(24.3)$ \\
\hline$B M I^{e}($ mean $\pm S D)$ & $21.2 \pm 3.3$ & $21.3 \pm 3.1$ & $21.1 \pm 3.3$ & $21.4 \pm 3.2$ & $20.7 \pm 3.2^{*}$ \\
\hline
\end{tabular}

$B M I$ body mass index, $S D$ standard deviation

$\wedge P<0.05$ in the Chi Square test or Fisher's exact test

* $P<0.05$ in $t$ test

a Number of cases with missing data: 34 for district of residence; 2 for education level, family income, and cancer in first-degree relatives; 1 for age group and smoking status

b Occasional consumer: $1-3$ days/week; frequent consumer: $\geq 4$ days/week

c Occasional consumer: $<1$ serving/day; frequent consumer: $\geq 1$ serving/day

d Never smoker: smoking $<20$ packs of cigarettes in a lifetime or $\leq 1$ cigarette per day for 1 year; former smoker: quit smoking $\geq 2$ years ago; current smoker: still smoking or quit $<2$ years ago

e Except this one, other values are presented as number of cases followed by percentage in parentheses

Table 2 Risk of lung cancer death in Chinese men in relation to the levels of alcohol consumption and dietary habits

\begin{tabular}{|c|c|c|c|c|c|}
\hline $\begin{array}{l}\text { Compo- } \\
\text { nent }\end{array}$ & $\begin{array}{l}\text { No. } \\
\text { of cases }\end{array}$ & $\begin{array}{l}\text { Unad- } \\
\text { justed HR }\end{array}$ & $95 \% \mathrm{Cl}$ & $\begin{array}{l}\text { Adjusted } \\
\mathrm{HR}^{\mathrm{C}}\end{array}$ & $95 \% \mathrm{Cl}$ \\
\hline \multicolumn{6}{|l|}{ Alcohola $^{\text {a }}$} \\
\hline Never & 391 & 1.00 & & 1.00 & \\
\hline Ever & 661 & 0.85 & $0.74-0.98$ & 0.83 & $0.70-0.98$ \\
\hline Occasional & 289 & 0.83 & $0.71-0.97$ & 0.82 & $0.68-0.97$ \\
\hline Frequent & 372 & 0.96 & $0.81-1.13$ & 0.91 & $0.73-1.14$ \\
\hline \multicolumn{6}{|c|}{ Preserved/fried food ${ }^{b}$} \\
\hline Occasional & 768 & 1.00 & & 1.00 & \\
\hline Frequent & 284 & 1.06 & $0.91-1.23$ & 1.20 & $1.00-1.42$ \\
\hline \multicolumn{6}{|c|}{ Fruits/vegetables ${ }^{b}$} \\
\hline Occasional & 667 & 1.00 & & 1.00 & \\
\hline Frequent & 385 & 1.00 & $0.87-1.15$ & 0.86 & $0.72-1.02$ \\
\hline \multicolumn{6}{|l|}{ Meat ${ }^{b}$} \\
\hline Occasional & 941 & 1.00 & & 1.00 & \\
\hline Frequent & 111 & 1.11 & $0.89-1.38$ & 1.27 & $0.98-1.64$ \\
\hline
\end{tabular}

$H R$ hazard ratio, $\mathrm{Cl}$ confidence interval

a Ever consumer: consumed alcoholic beverages in the year before cancer diagnosis; this group includes occasional and frequent consumer groups. Occasional consumer: 1-3 days/week; frequent consumer: $\geq 4$ days/week

b Occasional consumer: $<1$ serving/day; frequent consumer: $\geq 1$ serving/day

c Adjusted for district of residence, age at diagnosis, body mass index, cancer history in first-degree relatives, education level, family income, stage at diagnosis, smoking status, smoking pack-years, and treatment

evidence has shown that the habit of consuming fresh fruits and vegetables has a preventive effect on lung cancer [6]. Regarding the relationship between fruit and vegetable consumption and lung cancer prognosis, two small-scale studies indicated that frequent consumption of fruits or vegetables might be beneficial. Noticeably, the findings of one of these studies were not statistically significant [26]; the other one observed benefits only in women [27]. The benefit of fruit or vegetable consumption in lung cancer prognosis was supported by two more recent small trials, but they did not employ controls [28, 29]. Consumption of meat, especially red meat and preserved meat, has long been hypothesized to be carcinogenic; however, whether the frequent consumption of meat is related to lung cancer risk remains controversial [30]. High level of meat consumption is associated with the high intake of fat, endogenous carcinogens from heme, and exogenous carcinogens generated in the process of cooking and preservation [31]. These substances are presumed to function in the pathways of tumor progression. However, no relevant epidemiologic evidence has been presented.

A few studies have sought to determine how alcohol affects cancer prognosis. Of several mechanisms proposed, the immune system seems to be decisive. Alcohol affects the immune system in two opposite ways. When the alcohol dose is low, the immune system is stimulated to inhibit tumor growth; when the dose is high enough, alcohol leads to immune inhibition and promotes tumor progression [32]. This evidence may partly explain the U-shaped dose-responsive pattern observed in this study and in previous breast cancer studies [15]. Lowto-moderate alcohol consumption (practiced by occasional drinkers in this study) may initiate the first phase of the immune response, which restrains tumor growth and yields better survival, whereas heavy drinking (practiced by frequent drinkers in this study) may exceed the threshold and trigger the second phase, which promotes tumor progression.

Another possible explanation for the favorable lung cancer prognosis in alcohol drinkers is the variation of genes involved in the metabolism of alcohol and anticancer drugs. The frequency of alcohol consumption is related to the status of cytochrome P450 and glutathione 


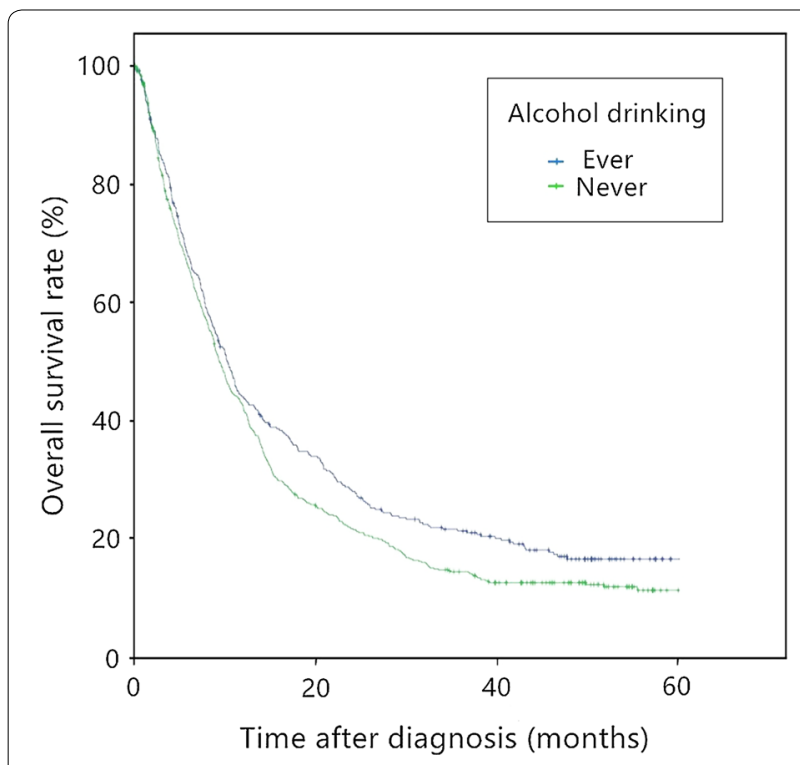

Fig. 1 Kaplan-Meier survival curves for Chinese men with lung cancer, grouped by level of alcohol consumption. Patients who ever regularly consumed alcohol before being diagnosed with lung cancer had a better prognosis than those who never consumed alcohol

S-transferase enzymes [17]. People with deficiencies in metabolism enzymes may experience unfavorable physical responses to alcohol, meaning that they will be unlikely to be regular drinkers. The primary alcohol metabolism cytochrome P450 is CYP2E1 [33]; CYP2E1 is also essential in the metabolism of the anti-cancer drugs cisplatin and etoposide [34, 35], which are frequently used in lung cancer chemotherapy. For SCLC, cisplatin plus etoposide is the prioritized first-line regimen [36]. Thus, lung cancer patients whose cytochrome P450 metabolism function is weak may have a low tolerance for chemotherapy; consequently, they may have a poor response to treatment and a shorter survival time. Moreover, before getting cancer, they are very unlikely to be regular drinkers.

Although there are controversies, the association between alcohol consumption and lung cancer risk has been well discussed. Earlier studies also focused on the effect of dietary habits on the incidence of lung cancer. Regarding lung cancer prognosis, it is well known that prognosis is associated with tumor characteristics (e.g., histologic subtypes and gene mutations), stage, and treatment. However, the prognostic values of alcohol consumption and dietary habits in lung cancer have either never been studied or studied only rarely. Thus, existing evidence shows that alcohol consumption and dietary habits are more related to the incidence of lung cancer than to prognosis. However, because lifestyle habits are modifiable, it is possible that the prognosis of lung cancer patients can be further improved by adopting more

Table 3 Adjusted risk of lung cancer death in relation to levels of alcohol consumption and dietary habits in Chinese men according to histologic subtypes

\begin{tabular}{|c|c|c|c|c|c|c|}
\hline \multirow[t]{2}{*}{ Component } & \multicolumn{3}{|l|}{ NSCLC } & \multicolumn{3}{|l|}{ SCLC } \\
\hline & No. of cases & Adjusted $\mathrm{HR}^{\mathrm{c}}$ & $95 \% \mathrm{Cl}$ & No. of cases & Adjusted HR ${ }^{c}$ & $95 \% \mathrm{Cl}$ \\
\hline \multicolumn{7}{|l|}{ Alcohol } \\
\hline Never & 349 & 1.00 & & 42 & 1.00 & \\
\hline Ever & 602 & 0.83 & $0.70-0.98$ & 59 & 0.52 & $0.28-0.96$ \\
\hline Occasional & 265 & 0.74 & $0.62-0.90$ & 24 & 0.63 & $0.31-1.29$ \\
\hline Frequent & 337 & 0.84 & $0.70-1.02$ & 35 & 1.37 & $0.66-2.79$ \\
\hline \multicolumn{7}{|c|}{ Preserved/fried food ${ }^{b}$} \\
\hline Occasional & 700 & 1.00 & & 68 & 1.00 & \\
\hline Frequent & 251 & 1.21 & $1.00-1.45$ & 33 & 1.12 & $0.62-2.05$ \\
\hline \multicolumn{7}{|c|}{ Fruits/vegetables $^{b}$} \\
\hline Occasional & 630 & 1.00 & & 37 & 1.00 & \\
\hline Frequent & 321 & 0.93 & $0.78-1.11$ & 64 & 0.74 & $0.41-1.34$ \\
\hline \multicolumn{7}{|l|}{ Meat ${ }^{b}$} \\
\hline Occasional & 848 & 1.00 & & 93 & 1.00 & \\
\hline Frequent & 103 & 1.19 & $0.92-1.58$ & 8 & 0.73 & $0.31-1.73$ \\
\hline
\end{tabular}

OR odds ratio, Cl confidence interval, NSCLC non-small cell lung cancer, SCLC small cell lung cancer

a Ever consumer: consumed alcoholic beverages in the year before cancer diagnosis; this group includes occasional and frequent consumer groups. Occasional consumer: 1-3 days/week; frequent consumer: $\geq 4$ days/week

b Occasional consumer: $<1$ serving/day; frequent consumer: $\geq 1$ serving/day

c Adjusted for district of residence, age at diagnosis, body mass index, cancer history in first-degree relatives, education level, family income, stage at diagnosis, smoking status, smoking pack-years, and treatment 
Table 4 Associations of alcohol consumption and dietary habits with lung cancer histology in 1052 patients

\begin{tabular}{|c|c|c|c|c|}
\hline \multirow[t]{2}{*}{ Component } & \multicolumn{2}{|c|}{ No. of cases (\%) } & \multirow[t]{2}{*}{ Adjusted $O^{c}$} & \multirow[t]{2}{*}{$95 \% \mathrm{Cl}$} \\
\hline & NSCLC & SCLC & & \\
\hline \multicolumn{5}{|l|}{ Alcohol $^{\mathrm{a}}$} \\
\hline Never & $349(33.2)$ & $42(4.0)$ & 1.00 & \\
\hline Ever & $602(57.2)$ & $59(5.5)$ & 1.48 & $0.97-2.24$ \\
\hline \multicolumn{5}{|c|}{ Preserved/fried food ${ }^{b}$} \\
\hline $\begin{array}{r}\text { Occasional (<1 } \\
\text { serving/day) }\end{array}$ & $700(66.5)$ & $68(6.5)$ & 1.00 & \\
\hline $\begin{array}{l}\text { Frequent ( } \geq 1 \\
\text { serving/day) }\end{array}$ & $251(23.9)$ & $33(3.1)$ & 0.50 & $0.33-0.76$ \\
\hline \multicolumn{5}{|l|}{ Fruits/vegetables $^{b}$} \\
\hline $\begin{array}{r}\text { Occasional (<1 } \\
\text { serving/day) }\end{array}$ & $630(59.9)$ & $37(3.5)$ & 1.00 & \\
\hline $\begin{array}{l}\text { Frequent ( } \geq 1 \\
\text { serving/day) }\end{array}$ & $321(30.5)$ & $64(6.1)$ & 0.62 & $0.41-0.95$ \\
\hline \multicolumn{5}{|l|}{ Meat ${ }^{b}$} \\
\hline $\begin{array}{c}\text { Occasional }(<1 \\
\text { serving/day) }\end{array}$ & $848(80.6)$ & $93(8.8)$ & 1.00 & \\
\hline $\begin{array}{l}\text { Frequent ( } \geq 1 \\
\quad \text { serving/day) }\end{array}$ & $103(9.8)$ & $8(0.8)$ & 0.93 & $0.46-1.88$ \\
\hline
\end{tabular}

OR odds ratio, $\mathrm{Cl}$ confidence interval, NSCLC non-small cell lung cancer, $S C L C$ small cell lung cancer

a Ever consumer: consumed alcoholic beverages in the year before cancer diagnosis

b Occasional consumer: $<1$ serving/day; frequent consumer: $\geq 1$ serving/day

c Adjusted for age at diagnosis and smoking status, using SCLC as the reference

healthful habits. Future larger studies that quantify the lifetime consumption of alcohol and foods are needed to verify our findings.

Our study did have several limitations. Selection bias is a concern, but it should not be a major issue. The distributions of age and histologic subtype of our patients were similar to those reported by the Hong Kong Cancer Registry. Because all patients in this study were Chinese men, one should be cautious about generalizing the results to women and to other races. Confounding from cigarette smoking and other related factors could also be a concern because drinking is generally associated with factors like smoking, age, education level, income, and social level. To minimize the confounding effect, we tried to adjust as many related factors as possible into the "base" regression model. In the final model, some social factors were not retained because the removal of them could not change the estimate by $10 \%$ or more in the backward stepwise survival analysis. However, the confounding effect may still be a concern because it is impossible to adjust for every potential confounder. Misclassification of alcohol and dietary consumption levels may be an issue; but this misclassification, if it does exist, should be regarded as a non-differential one, which may lead to an attenuated association. More detailed information on alcohol drinking and dietary habits, with quantity estimation and categorization, was not available because we thought that, in our pilot study, information on lifetime food and alcohol consumption from older men, especially, would not be accurate. This limitation prevented us from conducting further analyses.

In conclusion, we found that Chinese men who consumed alcohol occasionally prior to the diagnosis of lung cancer had a better prognosis than those who never drank alcohol. However, this survival benefit was not observed in frequent drinkers. In this population, frequent consumers of preserved or fried food had a higher risk of lung cancer death than occasional consumers. We suggest that future studies be conducted to confirm our findings.

\section{Authors' contributions}

WL analyzed the data and wrote the manuscript; LAT designed the study, ensured the quality, and reviewed the manuscript; JSKA managed patients and assisted in data collection; KSY collected data; FW performed data reanalysis; and ITSY designed the study. All authors read and approved the final manuscript.

Author details

${ }^{1} \mathrm{JC}$ School of Public Health and Primary Care, The Chinese University of Hong Kong, 4/F School of Public Health and Primary Care, Prince of Wales Hospital, Sha Tin, N.T., Hong Kong SAR, China. ${ }^{2}$ Department of Clinical Oncology, Hong Kong Adventist Hospital, Hong Kong SAR, China.

\section{Competing interests}

The authors declare that they have no competing interests.

Funding

This study was substantially supported by two grants from the Research Grants Council of the Hong Kong Special Administrative Region, China (No. CUHK4460/03M and No. CUHK4103/02M).

Received: 25 May 2016 Accepted: 21 January 2017

Published online: 10 February 2017

\section{References}

1. DeSantis CE, Lin CC, Mariotto AB, Siegel RL, Stein KD, Kramer JL, et al. Cancer treatment and survivorship statistics, 2014. CA Cancer J Clin. 2014;64(4):252-71. doi:10.3322/caac.21235.

2. Chen $W$, Zheng R, Zeng $H$, Zhang $\mathrm{S}$. The updated incidences and mortalities of major cancers in China, 2011. Chin JCancer. 2015;34(11):502-7. doi:10.1186/s40880-015-0042-6.

3. Chen $\mathrm{W}$, Zheng $\mathrm{R}$, Zeng $\mathrm{H}$, Zhang $\mathrm{S}$. The incidence and mortality of major cancers in china, 2012. Chin J Cancer. 2016;35(1):73. doi:10.1186/ s40880-016-0137-8.

4. LiYG, Gao X. Epidemiologic studies of particulate matter and lung cancer. Chin J Cancer. 2014;33(8):376-80. doi:10.5732/cjc.014.10063.

5. Tse LA, Yu IT, Wang XR, Qiu H, Au JS. Synergistic effect between alcohol consumption and familial susceptibility on lung cancer risk among Chinese men. PLoS ONE. 2012;7(7):e40647. doi:10.1371/journal. pone.0040647.

6. Bandera EV, Freudenheim JL, Vena JE. Alcohol consumption and lung cancer: a review of the epidemiologic evidence. Cancer Epidemiol Biomarkers Prev. 2001:10(8):813-21.

7. Linseisen J, Rohrmann S, Miller AB, Bueno-de-Mesquita HB, Buchner $F L$, Vineis $P$, et al. Fruit and vegetable consumption and lung cancer risk: updated information from the European Prospective Investigation into Cancer and Nutrition (EPIC). Int J Cancer. 2007;121(5):1103-14. doi:10.1002/ijc.22807. 
8. Wakai K, Matsuo K, Nagata C, Mizoue T, Tanaka K, Tsuji I, et al. Lung cancer risk and consumption of vegetables and fruit: an evaluation based on a systematic review of epidemiological evidence from Japan. Jpn J Clin Oncol. 2011;41(5):693-708. doi:10.1093/jjco/hyr027.

9. Sinha R, Kulldorff M, Curtin J, Brown CC, Alavanja MC, Swanson CA. Fried, well-done red meat and risk of lung cancer in women (United States). Cancer Causes Control. 1998;9(6):621-30.

10. Tasevska N, Sinha R, Kipnis V, Subar AF, Leitzmann MF, Hollenbeck AR, et al. A prospective study of meat, cooking methods, meat mutagens, heme iron, and lung cancer risks. Am J Clin Nutr. 2009;89(6):1884-94. doi:10.3945/ajcn.2008.27272.

11. Sinha R, Kulldorff M, Swanson CA, Curtin J, Brownson RC, Alavanja MC. Dietary heterocyclic amines and the risk of lung cancer among Missouri women. Cancer Res. 2000;60(14):3753-6.

12. Tse LA, Yu IT, Rothman N, Ji BT, Qiu H, Wang XR, et al. Joint effects of environmental exposures and familial susceptibility to lung cancer in Chinese never smoking men and women. J Thorac Oncol. 2014;9(8):1066-72. doi:10.1097/jto.0000000000000179.

13. Tse LA, Yu IT, Au JS, Yu KS, Kwok KP, Qiu H, et al. Environmental tobacco smoke and lung cancer among Chinese nonsmoking males: might adenocarcinoma be the culprit? Am J Epidemiol. 2009;169(5):533-41. doi:10.1093/aje/kwn385.

14. Tse LA, Yu IS, Au JS, Qiu H, Wang XR. Silica dust, diesel exhaust, and painting work are the significant occupational risk factors for lung cancer in nonsmoking Chinese men. Br J Cancer. 2011;104(1):208-13. doi:10.1038/ sj.bjc.6606006.

15. Newcomb PA, Kampman E, Trentham-Dietz A, Egan KM, Titus LJ, Baron $J A$, et al. Alcohol consumption before and after breast cancer diagnosis: associations with survival from breast cancer, cardiovascular disease, and other causes. J Clin Oncol. 2013;31(16):1939-46. doi:10.1200/ jco.2012.46.5765.

16. Barnett GC, Shah M, Redman K, Easton DF, Ponder BA, Pharoah PD. Risk factors for the incidence of breast cancer: do they affect survival from the disease? J Clin Oncol. 2008;26(20):3310-6. doi:10.1200/jco.2006.10.3168.

17. Reding KW, Daling JR, Doody DR, O'Brien CA, Porter PL, Malone KE. Effect of prediagnostic alcohol consumption on survival after breast cancer in young women. Cancer Epidemiol Biomarkers Prev. 2008;17(8):1988-96. doi:10.1158/1055-9965.epi-07-2897.

18. Chao C. Associations between beer, wine, and liquor consumption and lung cancer risk: a meta-analysis. Cancer Epidemiol Biomarkers Prev. 2007;16(11):2436-47. doi:10.1158/1055-9965.epi-07-0386.

19. Barron CC, Moore J, Tsakiridis T, Pickering G, Tsiani E. Inhibition of human lung cancer cell proliferation and survival by wine. Cancer cell Int. 2014;14(1):6. doi:10.1186/1475-2867-14-6.

20. Briviba K, Pan L, Rechkemmer G. Red wine polyphenols inhibit the growth of colon carcinoma cells and modulate the activation pattern of mitogen-activated protein kinases. J Nutr. 2002;132(9):2814-8.

21. Janghorbani M, Ho SY, Lam TH, Janus ED. Prevalence and correlates of alcohol use: a population-based study in Hong Kong. Addiction. 2003;98(2):215-24.
22. Ishii Y, Matsushita K, Kuroda K, Yokoo Y, Kijima A, Takasu S, et al. Acrylamide induces specific DNA adduct formation and gene mutations in a carcinogenic target site, the mouse lung. Mutagenesis. 2015;30(2):22735. doi:10.1093/mutage/geu062.

23. Tran DC, Brazeau DA, Nickerson PA, Fung HL. Effects of repeated in vivo inhalant nitrite exposure on gene expression in mouse liver and lungs. Nitric Oxide. 2006;14(4):279-89. doi:10.1016/j.niox.2005.09.010.

24. Karimzadeh L, Koohdani F, Siassi F, Mahmoudi M, Moslemi D, Safari F. Relation between nitrate and nitrite food habits with lung cancer. J Exp Ther Oncol. 2012;10(2):107-12.

25. Colakogullari M, Ulukaya E, Yilmaztepe A, Ocakoglu G, Yilmaz M, Karadag $M$, et al. Higher serum nitrate levels are associated with poor survival in lung cancer patients. Clin Chem. 2006;39(9):898-903. doi:10.1016/j. clinbiochem.2006.06.008.

26. Skuladottir H, Tjoenneland A, Overvad K, Stripp C, Olsen JH. Does high intake of fruit and vegetables improve lung cancer survival? Lung Cancer. 2006;51(3):267-73. doi:10.1016/j.lungcan.2005.06.009.

27. Goodman MT, Kolonel LN, Wilkens LR, Yoshizawa CN, Le Marchand $\mathrm{L}$, Hankin JH. Dietary factors in lung cancer prognosis. Eur J Cancer. 1992;28(2-3):495-501.

28. Sun AS, Ostadal O, Ryznar V, Dulik I, Dusek J, Vaclavik A, et al. Phase I/ II study of stage III and IV non-small cell lung cancer patients taking a specific dietary supplement. Nutr Cancer. 1999;34(1):62-9. doi:10.1207/ s15327914nc340109.

29. Sun $A S$, Yeh HC, Wang LH, Huang YP, Maeda H, Pivazyan A, et al. Pilot study of a specific dietary supplement in tumor-bearing mice and in stage IIIB and IV non-small cell lung cancer patients. Nutr Cancer. 2001;39(1):85-95. doi:10.1207/S15327914nc391_12.

30. Koutsokera A, Kiagia M, Saif MW, Souliotis K, Syrigos KN. Nutrition habits, physical activity, and lung cancer: an authoritative review. Clin Lung Cancer. 2013;14(4):342-50. doi:10.1016/j.cllc.2012.12.002.

31. Ferguson LR. Meat and cancer. Meat Sci. 2010;84(2):308-13. doi:10.1016/j. meatsci.2009.06.032.

32. Zhang H, Zhu Z, Zhang F, Meadows GG. Alcohol consumption and antitumor immunity: dynamic changes from activation to accelerated deterioration of the immune system. Adv Exp Med Biol. 2015;815:313-31. doi:10.1007/978-3-319-09614-8_18.

33. Cederbaum Al. CYP2E1-biochemical and toxicological aspects and role in alcohol-induced liver injury. Mount Sinai J Med N. Y. 2006;73(4):657-72.

34. Ahmed EM, EL-Maraghy SA, Teleb ZA, Shaheen AA. Pretreatment with turmeric modulates the inhibitory influence of cisplatin and paclitaxel on CYP2E1 and CYP3A1/2 in isolated rat hepatic microsomes. Chemico-Biol Interact. 2014;220:25-32. doi:10.1016/j.cbi.2014.05.007.

35. Kawashiro T, Yamashita K, Zhao XJ, Koyama E, Tani M, Chiba K, et al. A study on the metabolism of etoposide and possible interactions with antitumor or supporting agents by human liver microsomes. J Pharmacol Exp Ther. 1998;286(3):1294-300.

36. Morabito A, Carillio G, Daniele G, Piccirillo MC, Montanino A, Costanzo $R$, et al. Treatment of small cell lung cancer. Crit Rev Oncol Hematol. 2014;91(3):257-70. doi:10.1016/j.critrevonc.2014.03.003.

\section{Submit your next manuscript to BioMed Central and we will help you at every step:}

- We accept pre-submission inquiries

- Our selector tool helps you to find the most relevant journal

- We provide round the clock customer support

- Convenient online submission

- Thorough peer review

- Inclusion in PubMed and all major indexing services

- Maximum visibility for your research

Submit your manuscript at www.biomedcentral.com/submit 